\title{
An Approximate Model for Cancellous Bone Screw Fixation
}

Brown, C.J. ${ }^{\dagger 1}$, Maclnnes, R.A. ${ }^{1}$, Day, A. ${ }^{2}$, Hess, B. ${ }^{3}$, Procter, P. ${ }^{1,4}$

${ }^{1}$ School of Engineering and Design, Brunel University, Uxbridge, UB8 3PH, UK.

${ }^{2}$ Brunel University, now IDAC Ltd, Airport House, Purley Way, Croydon, CR0 0XZ, UK.

${ }^{3}$ Stryker Osteosynthesis, Boetzingerstrasse 41, Freiburg, Germany 79111

${ }^{4}$ Stryker Osteosynthesis, Le Lumion, Rue Francois Peyrot 12,

$\mathrm{CH}-1218$ Grand Saconnex, Switzerland

† Author to receive correspondence

Keywords: Cancellous bone screw, augmentation, calcium phosphate cement, finite element modelling, screw fixation.

\begin{abstract}
This paper presents a finite element (FE) model to identify parameters that affect the performance of an improved cancellous bone screw fixation technique, and hence potentially improved fracture treatment. In cancellous bone of low apparent density it can be difficult to achieve adequate screw fixation and hence provide stable fracture fixation that enables bony healing. Data from predictive FE models indicate that cements can have significant potential to improve screw holding power in cancellous bone. These FE models are used to demonstrate the key parameters that determine pullout strength in a variety of screw, bone, and cement set-ups, and to compare the effectiveness of different configurations. The paper concludes that significant advantages, up to an order of magnitude, in screw pull-out strength in cancellous bone might be gained by the appropriate use of a currently- approved calcium phosphate cement.
\end{abstract}




\section{Introduction}

The increasingly variable nature of bone in an ageing patient population demands new approaches to ensure adequate fixation of medical devices that rely upon screws for their attachment to bone $[1,8]$. This is because normal cancellous bone has a wide range of properties. The apparent density of human bone may range from that which is considered strong and healthy (approximately $0.45 \mathrm{~g} / \mathrm{cm}^{3}$ ) to that which is comparatively weak (approximately $0.15 \mathrm{~g} / \mathrm{cm}^{3}$ ) [23, 28, 36]. The term osteoporotic, widely used to describe weak bone that might have almost no mechanical strength, is often rather loosely defined. However a precise definition of the terms osteopenic and osteoporotic as described by the WHO definition [46] is based on T-scores of the population. This references against the areal bone density of a healthy young individual in the population. Osteopenic is defined as having a T-score between -1 and -2.5 while osteoporotic bone has a T-score of less than -2.5 .

The majority of implants used in the fixation of fractures and deformity corrections attach to the bone via various screw threads; such devices include bone plates, intramedullary nails and external fixators. While the basic bone structure is comprised of cancellous bone with an overlying cortical shell, it is the cancellous bone that frequently presents the main interface with the implant either due to the removal or compromised nature of the cortical shell during surgery. Hence cancellous bone acts as a major component of any loadbearing fixation. Where the load-carrying capacity of cancellous bone is inadequate, clinical failures may often occur, resulting in failure modes such as stripping on insertion, pullout, migration and loosening. These failure modes are typically reported in the range 3 to $5 \%$ [40] as a percentage of all failure. The authors estimate that approximately 100 million screws are implanted worldwide per year which suggests that screw fixation failure is a numerically significant problem. The work presented here critically assesses variables that influence enhanced cancellous bone screw fixation and specifically tests the hypothesis that clinically useful augmentation of cancellous bone can be achieved with relatively small volumes of cement by comparing the results from a range of FE models.

\section{Review of literature:}

When faced with the need to enhance cancellous bone screw fixation in low quality and/or compromised cancellous bone, the surgeon has a limited number of options. These are essentially to change the bone, to change the number of screws, to change the screw characteristic (e.g. length, radius, thread angle, etc.), or to change the interface between screw and bone. For example, it also appears feasible to change bone quality adjacent to 
a screw post surgery, and improve pullout strength using an antiporotic drug, such as a bisphosphonate [4, 34].

One method therefore involves creating a more effective mechanical connection. This can be achieved by selecting screws of different length (although changing the length of screw engaged can be impossible in certain clinical situations) and to a lesser extent other thread dependent design factors [3, 45, 9, 21, 12, 11]. A new screw design is usually compared with an existing predicate device. Where a theoretical approach has been used to design screws it is often based on engineering design principles for machine screws in conventional engineering materials. For example, Asnis' [3] well-cited work on cancellous screw design uses a formula that is taken directly from engineering texts for screws in isotropic continuous media [5]. This may be appropriate for very dense cancellous bone or cortical bone, but is less certain for low density or osteoporotic cancellous bone. Therefore, whilst predicted screw pullout forces in cortical bone are in good agreement with those experimentally obtained, in cancellous bone there is less evidence that such an approach is justified.

The remaining alternative is to engage with the cancellous bone at a larger diameter. This can be done by either using a larger screw (though again this may not be possible in the clinical situation) or by increasing the effective diameter at which the screw engages with the bone. In this paper the term 'screw augmentation' is used to describe the addition of cement to the bone adjacent to the screw. Strictly speaking, it is the bone that is augmented and there is no change to the screw itself. Nevertheless, the common usage of the term screw augmentation appears already established [33, 32, 41] in cancellous bone and will be used here to describe configurations of screw and cement.

The interface between the screw and the surrounding cancellous bone can be modified using bone dilation, a technique that involves the impaction of a layer of healthy cancellous bone adjacent to the implant which then forms a denser matrix around the screw that is capable of transferring greater loads to the surrounding cancellous bone. The effective engaged diameter is increased as a result. Another increasingly common method for improving screw fixation reported in recent years is the addition of a cement of some kind into a predrilled hole. However the optimal relationship between cement distribution and strength properties has hitherto only been explored in an empirical manner. Studies have investigated the use of PMMA [ 44,32,18,6,10,20] while others have investigated the use of calcium phosphate cements $[14,29]$ or calcium sulphate cements $[24,22]$ and compared these bioresorbable/biodegradable cements to PMMA [22,35]. 
Many of the studies are based on in vitro tests. The ASTM standard for determination of screw pullout forces, ASTM F-543 [5], specifies the use of closed pore synthetic cancellous bone. It is obvious however, that testing using such materials does not produce data appropriate to either the experimental configuration (where the penetration of cement into the pores is critical) or the clinical application, and pullout forces reported can be higher than expected.

In clinical practice it is not known how small an amount of injected cement per screw might be used to ensure screw augmentation, and what levels of confidence might apply to augmentation where minimal quantities are used. The technique has been used where there is poor bone quality primarily in spinal and traumatology applications [16, 26, 22, 44]. However, despite the apparent widespread clinical use, the practice of screw augmentation appears to be largely empirical and trial and error is most often used to establish the amount and the position of the cement.

The primary objective of this paper is to examine contact between screw and cancellous bone, but it is known that the interaction between cortical and cancellous bone is also important. A study [42] in a limited series of human cadaver tibiae examining screw pullout force, found that the holding power of a screw was affected not only by the quality of the underlying cancellous bone but also by the proximity of the screw to the overlying cortical shell. That work also concluded that the role of the overlying cortical shell was particularly significant for shell thicknesses over $1.5 \mathrm{~mm}$. This is one of the few publications in which the key role of the cortical shell has been reported and whilst it seems obvious that this should be considered it has often been neglected in other experimental work presented in the literature.

Surprisingly, little current literature contains any comprehensive FE models where both the screw and the trabecular micro-architecture are considered in contact, although there are many contributions where both components are treated in isolation [19, 22, 31]. Recent presentations have shown promising initial results for models for load sharing between bone and implant using full 3 -d cancellous bone representation $(38,37)$, while others have focused on developing approximate methods for modelling the microarchitecture (15).

The present study uses a simplified FE model to systematically examine parameters. The FE method is well established (e.g. $25,43,17$ ) and is often used, when validated, to give quantitative analyses. The use of the simplified model presented here does not have that 
aim, but instead adopts a comparative approach to give an estimate of the relative importance of key parameters.

\section{Materials and Methods \\ Finite Element Modelling}

A 2-D axisymmetric finite element model with approximately 75,000 elements was developed using ANSYS [2] software. Two dimensional modelling was adopted in order to develop preliminary models of the problems with the intention of later migrating to a fully 3-dimensional model. The configuration used is shown in Figure 1. Commonly cancellous architecture is assumed to act as a continuum, but in this work an approach that includes some effect of individual trabeculae is required.

The screw adopted as a "standard" in the model, and in subsequent pull-out tests and animal studies (described elsewhere) was a Stryker $4 \mathrm{~mm}$ diameter cancellous bone screw (Stryker item No. 325044S). This choice was mainly determined because it was the largest screw practicable for use in subsequent lapine animal study tests, but further explanation is given below. The cancellous bone was modelled with square modules representing the individual trabecular cells. In most cases studied, the wall thickness was $0.1 \mathrm{~mm}$ and the standard cell size was set at $1.0 \times 1.0 \mathrm{~mm}$. The bone was assumed to be reamed to the mean of the inner and outer screw diameter before screw insertion. Variants with a smaller $(0.8 \times 0.8 \mathrm{~mm})$ cell size were also evaluated. Any cortical shell present was modelled as a continuous layer overlying the cancellous model and rigidly connected to it at points of contact. For the cortical shell, the screw was modelled as a single thread normally engaging midway through the cross-section, and the importance of this position parameter was examined as part of the study (Figure 1). The consequence of the 2-D model is that the full structure presents as a series of concentric tubes, lacking radial stiffeners, but also lacking radial perforations.

The bone properties were taken as bi-linear. For cortical bone the elastic modulus was 9.5 $\mathrm{GPa}$ while for cancellous the value was $1.1 \mathrm{GPa}$ [13]. Corresponding yield stresses were taken as $90 \mathrm{MPa}$ and $35 \mathrm{MPa}$. Poisson's ratio was 0.3 throughout [7]. The post-yield phase was assumed to have a modulus of $10 \%$ of the initial modulus. Where calcium phosphate cement is present the elastic modulus has been measured as $1.5 \mathrm{GPa}$ [27]. 
Radial penetration of the cement was modelled by filling some of the cells with a material that was again rigidly connected to any surrounding bone it contacted. This filling was implemented in the model so that radially either a complete cell or half cells could be filled (Figure 2). Contacts between the screw and any bone or cement elements were modelled as frictional using surface to surface contact modelling with 0.5 as the coefficient of friction unless otherwise stated.

Loading was applied by enforcing displacement of the screw head out of the restrained bone; consequent reaction loads are then found. This is often a more appropriate strategy for models with significant non-linearity. Displacements of up to $1 \mathrm{~mm}$ were applied in increments at the free end of the screw. This non-linearity of the material and the nonlinear behaviour of the contact model mean that failure is not easily defined. For the purposes of this study loads on models without a cortical shell are taken at a displacement of $0.5 \mathrm{~mm}$ which, in most cases, represents load at which initial non-linearity is evidenced. For models with a cortical shell, displacements are lower and loads are higher; where appropriate the associated displacement for given loads has been noted in the text.

\section{Results}

The finite element model enabled comparative examination of key parameters. First, it was expected that pullout strength would be dependent on embedded screw length and that there might be a linear function to relate screw length to force. This is shown in Figure 3 which examines pull-out strength for 3 lengths of $4 \mathrm{~mm}$ screw for both augmented and non-augmented systems, from which it is evident that a linear relationship exists for both the non-augmented and the augmented system.

A second feature that was examined was cell size. Figure 4 shows the effect of using a smaller cell size; on the left of the figure the bone augmentation effect is shown for a 0.8 $\mathrm{mm}$ cell while on the right it is shown for a $1 \mathrm{~mm}$ cell. The same cross-section size of trabecular strut was maintained in both cases. The smaller cell size gives an advantage because there are more trabecular struts for the thread to engage with. In all cases studied, the use of even a small amount of augmentation material led to a noticeable increase in pull-out strength. The suggested mechanism for this strength increase is that the trabecular struts that engage with the screw are shorter and hence stiffer and stronger.

Table 1 gives the pull-out forces for a range of cortical thickness. All the augmented screws included cement to half a cell away from the valley of the thread, but the same 
trend is seen for other degrees of radial augmentation. The thickness of the cortical shell present is varied from 0.5 to $2.0 \mathrm{~mm}$ and the presence of even a thin cortical shell can make a large difference to the pull-out force.

The extent to which augmentation material spreads radially is also important. Figure 5 shows the pullout force for varying radial augmentation. Big strength gains can be obtained from augmenting out to two cells (in this case about one screw radius). This effectively doubles the shear area in this case, and hence the pullout force (although in practice such radial penetration of cement may be difficult to achieve). Even the effect of filling between the thread pitch of the screw, i.e. filling the valleys of the thread, seems to be effective in increasing pull-out force, and this is to some extent confirmed by other studies [30] that have investigated thread profile. This is supported by a more detailed consideration of the interface between screw and the individual trabeculae. Figure 6 shows the effect of changing the frictional characteristics at the screw surface. In Figure $6 \mathrm{a}$ the interface between screw and bone is fixed (i.e. does not allow movement or rotation) while in Figure $6 \mathrm{~b}$ the interface is frictional. The case shown is for no cortical layer, and the consequential pull-out force for this example (20 mm long screw) is increased by about $30 \%$ for the fixed condition; for cases where there is a cortical layer the effect is, of course, much reduced. This in turn indicates the importance of the interface condition, and suggests the potential importance of the cement adjacent to the screw. Any other variation of friction coefficient seems to have no effect unless the pullout force is very low (again associated with no cortical layer) and the friction coefficient is also very low.

\section{Discussion}

Finite element (FE) modelling was chosen as a means of evaluating the relative importance of the variables that affect screw pullout. Whilst this has been exhaustively done through empirical testing of screws in a variety of test materials (e.g. 11) the relationship between the main screw thread parameters has not been assessed for cancellous structures with an overlying cortical shell. One advantage of an FE model is that it enables the contributions of screw, bone, and cement properties to be varied and their effect on screw holding power to be more readily assessed than extensive physical testing would allow. However, it is not suggested that this is an absolute measure without validation.

The FE model demonstrates that selected parameters appeared to influence the pullout strength. In particular, length of screw engagement gives greater pull-out strength, 
increased cell size (and by analogy greater osteoporosity) reduces pullout strength, and radial penetration of cement increases pullout strength considerably. It has also demonstrated the importance of the interface contact between bone and screw, and suggests the importance of even the smallest cement layer adjacent to the screw.

This study has found that the most significant influence on augmentation was the presence (or removal) of the cortical shell. The FE model was able to examine the effect of connection between the cortical shell and the screw, and conclude that even if the screw is not connected directly to the shell, the stiffening effect of the overlying layer can be important to pull-out force especially if augmentation material is present (Figure 7). This outcome is consistent with the work of others [39], and is of significance when dealing with methods of cement delivery and tests that follow because the delivery of cement to layers immediately underlying the cortical shell can be really effective in transferring load to the shell [41]. So as far as the cortex is concerned the adjacent cement increases its effective thickness and the contribution to pullout resistance. Any over-drilling of the cortical shell might significantly reduce the pull-out strength and this result is of importance to both clinical practice and in-vitro testing.

\section{Conclusions}

FE models have been used to examine the parametric variations in screw pullout. The key to the use of augmentation material is to increase the effective radius at which pull-out failure will occur. In the presence of a cortical shell that is not over-drilled, this effect can be very significant.

The beneficial effect of augmentation has been clearly demonstrated in all the results, and the comparative modelling has presented important insights into possible protocols and processes for in-vitro testing in real bone. In particular the importance of preserving a cortical shell in work involving real bone is emphasized. This may be clinically important where a technique involves either removal of a cortical shell (countersinking to reduce screw head protrusion) or weakening (over drilling to allow a lag effect between bone fragments). 


\section{References}

1. Andersson $S$, Rodrigues $M$, Olerud $C$, Odontoid fractures: high complication rate associated with anterior screw fixation in the elderly, European Spine Journal, Vol. 9, No.1, (2000) p.56-59

2. ANSYS, ANSYS® Academic Research, Release 11.1 (2009)

3. Asnis SE, Ernberg JJ, Bostrom M, Wright TM, Harrington RM, Tencer A, Peterson M, Cancellous Bone Screw Thread Design and Holding Power, Journal of Orthopaedic Trauma, Vol. 10, No. 7 (1996) p.462-469.

4. Aspenberg P, Wermelin K, Tengwall P, Fahlgren A, Additive effects of PTH and bisphosphonates on the bone healing response to metaphyseal implants in rats, Acta Orthopaedica, Vol. 79, No. 1, (2008) p.111-115

5. ASTM F543-07e1; Standard Specification and Test Methods for Metallic Medical Bone Screws.

6. Augat P, Rapp S, and Claes L, A Modified Hip Screw Incorporating Injected Cement for the Fixation of Osteoporotic Trochanteric Fractures, J. Orth Trauma, Vol 16, No5, PP311-316, 2002

7. Bagge $\mathrm{M}, \mathrm{A}$ model of bone adaptation as an optimization process, Journal of Biomechanics, Vol. 33, Issue 11 (2000) p.1349-1357

8. Berlemann U, Schwarzenbach $\mathrm{O}$, Dens fractures in the elderly: Results of anterior screw fixation in 19 elderly patients, Acta Orthopaedica, Vol. 68, No. 4, (1997) p.319-324

9. Brown GA, McCarthy T, Bourgeault CA, Callahan DJ, Mechanical Performance of Standard and Cannulated 4.0-mm Cancellous Bone Screws, J Orth Res, vol 18, pp307312,2000

10. Burval DJ, McLain RF, Milks R, Inceoglu S, Primary Pedicle Screw Augmentation in Osteoporotic Lumbar Vertebrae: Biomechanical Analysis of Pedicle Fixation Strength, Spine, Vol. 32, No. 10 (2007) p.1077-1083

11. Chapman JR, Harrington RM, Lee KM, Anderson PA, Tencer AF, Kowalski D, Factors Affecting the Pullout Strength of Cancellous Bone, J Biomechanical Eng'g, Vol 118, pp391-398, August 1996

12. Chen LH, Tai CL, Lai PL, Lee DM, Tsai TT, Fu TS, Niu CC, and Chen WJ, Pullout strength for cannulated pedicle screws with bone cement augmentation in severely osteoporotic bone: influences of radial hole and pilot hole tapping, Clinical Biomechanics, vol24 no9 pp781-785

13. Choi K, Kuhn JL, Ciarelli MJ, Goldstein SA., The elastic moduli of human subchondral, trabecular, and cortical bone tissue and the size-dependency of cortical bone modulus, J. Biomech., Vol.23 Issue 11 (1990) p.1103-13.

14. Collinge C, Merk B, and Lautenschlager EP, Mechanical Evaluation of Fracture Fixation Augmented with Tricalcium Phosphate Bone Cement in a Porous Osteoporotic Cancellous Bone Model, J Orth Trauma, Vol21 No 2, pp 124-128, Feb 2007

15. Dagan D., Be'ery M., and Gefen A., Single-trabecula building blocks for large-scale fineite element models of cancellous bone. J. Medical and Biological Engineering and Computing, vol. 42, pp549-556, 2004

16. Eriksson F, Mattsson P, Larsson S, The Effect of Augmentation with Resorbable or Conventional Bone Cement on the Holding Strength for Femoral Neck Fracture Devices, J Orth Trauma, Vol 16, No 5, pp302-310, 2002

17. Feerick EM., Mullett H., Fitzpatrick D., and McGarry J.P., Experimental and Computational Investigation of the Failure Mechanisms leading to Screw Pullout in Cortical Bone, Poster 1054, ORS Annual Meeting, Long Beach, USA, 2011.

18. Flahiff CM, Gober GA, Nicholas RW, Pullout strength of fixation screws from polymethylmethacrylate bone cement, Biomaterials, Vol 16, No 7, pp533-536, 1995

19. Foldager C, Bendtsen M, Nygaard J, Zou X, Bünger C, Differences in early osteogenesis and bone micro-architecture in anterior lumbar interbody fusion with rhBMP-2, equine bone protein extract, and autograft, Bone, Volume 45, Issue 2 (2009) p. 267-273 
20. Frakenburg EP, Goldstein SA, Bauer TW, Harris SA, Poser RD, Biomechanical and Histological Evaluation of a Calcium Phosphate Cement, The Journal of Bone and Joint Surgery, Vol.80 (1998) p.1112-24

21. Gausepohl T, Möhring R, Pennig D, Koebke J Fine thread versus coarse thread - A comparison of the maximum holding power Injury, Int. J. Care Injured 32 (2001) SD1SD7

22. Gefen A, Optimizing the biomechanical compatibility of orthopedic screws for bone fracture fixation, Medical Engineering \& Physics, Volume 24, Issue 5 (2002) p.337

23. Gibson L J, Ashby M F, Cellular Solids: Structure and Properties, Edition 2, revised, (1999), Cambridge University Press,.

24. Griffon DJ, Stoller A, Schaeffer DJ, Seddighi MR, Johnson AL, Kurath P, Evaluation of 2 Cement Techniques for Augmentation of Stripped 1.5mm screw sites in the distal metaphysic of Feline Radii. Veterinary Surgery, Vol 34, (2005) pp223-230,

25. Harrison NM., McDonnell PF., O'Mahoney DC., Kennedy OD., O'Brien FJ., and McHugh PE., Heterogeneous linear elastic trabecular bone modelling using microCT attenuation data and experimentally measured heterogeneous tissue properties, J Biomechanics, 41 (2008) 2589-2596.

26. Horstmann WG, Verheyen CCPM, Leemans R, An injectable calcium phosphate cement as a bone-graft substitute in the treatment of displaced lateral tibial plateau fractures, Injury, Int. J. Care Injured Vol.34 (2003) p141-144

27. Ikenaga $M$, Hardouin $P$, Lemaître $J$, Andrianjatovo $H$, Flautre $B$, Biomechanical characterization of a biodegradable calcium phosphate hydraulic cement: A comparison with porous biphasic calcium phosphate ceramics, Journal of Biomedical Materials Research, Vol. 40, No. 1 (1998) p.139-144

28. Keaveny TM, Wachtel EF, Ford CM, Hayes WC. Differences between the tensile and compressive strengths of bovine tibial trabecular bone depend on modulus. $\mathrm{J}$ Biomech. (1994) Sep;27(9):1137-46.

29. Leung KS, Siu WS, Li SF, Qin L, Cheung WH, Tam KF, Lui PP., An in vitro optimized injectable calcium phosphate cement for augmenting screw fixation in osteopenic goats, J Biomed Mater Res B Appl Biomater., Vol.78, No.1, (2006) p.153-160

30. Mader K, Pennig D, Gausepohl T, Patsalis T. Calcaneotalotibial arthrodesis with a retrograde posterior-to-anterior locked nail as a salvage procedure for severe ankle pathology. J Bone Joint Surg Am. Suppl. 4 (2003) p.123-8

31. McDonnell P, Harrison N, Lohfeld S, Kennedy O, Zhang Y, McHugh PE, Investigation of the mechanical interaction of the trabecular core with an external shell using rapid prototype and finite element models, J Mechanical Behaviour of Biomedical Materials, 2010, v3, pp63-76

32. McKoy BE, An YH, An Injectable Cementing Screw for Fixation in Osteoporotic Bone, J Biomed Materials Research Vol53 p216-220, 2000

33. Moore DC, Frankenburg EP, Goulet JA, Goldstein SA, Hip Screw Augmentation with an In Situ-Setting Calcium Phosphate Cement: An In Vitro Biomechanical Analysis, Journal of Orthopaedic Trauma, Vol. 11, Issue 8 (1997) p.577-583

34. Procter $P$, Implant Coatings as a Means of Delivering Pharmaceuticals, European Cells and Materials Vol. 17. Suppl. 1, 2009, p4, ISSN 1473-2262

35. Renner SM, Lim T-H, Kim W-J, Katolik L, An HS, Andersson GBJ, Augmentation of Pedicle Screw Fixation Strength Using an Injectable Calcium Phosphate Cement as a Function of Injection Timing and Method, Spine, Vol. 29, No. 11 (2004) p.E212-E216

36. Rincon Kohli $L$, Identification of a multiaxial failure criterion for human trabecular bone. Faculté Sciences et Technique de l'Ingénieur, Institut de genie biomedical, section de genie mécanique, Lausanne, Switzerland, Ecole polytechnique Federale de Lausanne : PhD Thesis. 2003.

37. Ruffoni, D., Steiner, J., Wirth, A., Mueller T.L., Goldhahn J., Müller, R., van Lenthe, G. How does Cement Augmentation Increase the Mechanical Properties of Trabecular Bone? Poster 1541, ORS Annual Meeting, 2011, Long Beach, Ca. 
38. Ruffoni, D., Steiner, J., Wirth, A., Müller, R., van Lenthe, G. (2010). Quantifying the contribution of cortical and trabecular bone for implant anchorage - a microstructural finite element study in human vertebral bone. 17th Congress of the European Society of Biomechanics. Edinburgh, United Kingdom, 5-8 July 2010.

39. Seebeck J, Goldhahn J, Morlock MM, Schneider E, Mechanical behavior of screws in normal and osteoporotic bone, Osteoporos. Int. Vol.16 (2005), p.S107-S111.

40. Singer B R, McLauchlan G J, Robinson C M, Christie J, Epidemiology of fractures in 15,000 adults - the influence of age and gender (1998). JBJS

41. Stadelmann V.A., Bretton E., Terrier A and Pioletti D.P., Calcium phosphate cement augmentation of cancellous bone screws can compensate for the absence of cortical fixation. J. Biomechanics, vol. 43, No 15, pp. 2869-74, 2010.

42. Thiele OC, Echhardt C, Linke B, Schneider E, Factors affecting the stability of screws in human cortical osteoporotic bone, JBJS Vol. 89-B, No 5, (2007) p.701705.

43. Van Rietbergen B., Weinans H., Huiskes R., and Odgaard A., A new method to determine trabecular bone elastic properties and loading using micromechanical finite element models, J Biomechanics, 28 (1995) 69-81.

44. Verlaan J-J, Oner FC, Dhert WJA, Anterior spinal column augmentation with injectable bone cements, Biomaterials Vol.27 (2006) p290-301

45. Wang Y, Mori R, Ozoe N, Nakai T, Uchio Y, Proximal half angle of the screw thread is a critical design variable affecting the pull-out strength of Cancellous bone screws, Clinical Biomechanics, vol. 24, pp781-785, 2009.

46. World Health Organisation, Prevention and Management of Osteoporosis, Technical Report 921, Geneva, 2003. 


\begin{tabular}{|c|c|c|c|c|c|c|c|c|}
\hline \multirow[b]{3}{*}{$\begin{array}{c}\text { Screw } \\
\text { length } \\
(\mathrm{mm})\end{array}$} & \multicolumn{8}{|c|}{ Pull-out strength (N) } \\
\hline & \multicolumn{4}{|c|}{ Non-Augmented } & \multicolumn{4}{|c|}{ Augmented } \\
\hline & $\begin{array}{c}\text { No } \\
\text { cortex }\end{array}$ & $\begin{array}{l}0.5 \mathrm{~mm} \\
\text { cortex }\end{array}$ & $\begin{array}{l}1.0 \mathrm{~mm} \\
\text { cortex }\end{array}$ & $\begin{array}{l}2.0 \mathrm{~mm} \\
\text { cortex }\end{array}$ & $\begin{array}{c}\text { No } \\
\text { cortex }\end{array}$ & $\begin{array}{l}0.5 \mathrm{~mm} \\
\text { cortex }\end{array}$ & $\begin{array}{l}1.0 \mathrm{~mm} \\
\text { cortex }\end{array}$ & $\begin{array}{l}2.0 \mathrm{~mm} \\
\text { cortex }\end{array}$ \\
\hline 10 & 37.4 & 183.1 & 407.2 & 891.7 & 96.8 & 220.1 & 473.3 & 1140.3 \\
\hline 20 & 162.1 & 256.4 & 417.9 & 884.1 & 183.8 & 281.1 & 557.5 & 1126.5 \\
\hline 30 & 134.3 & 344.9 & 545.4 & 1178.8 & 260.0 & 369.7 & 637.7 & 1260.1 \\
\hline
\end{tabular}

\section{Captions to Tables}

Table 1 - Pull-out strengths $(\mathrm{N})$ from FE models for different screw lengths and cortical bone thickness. 
Page 13

\section{Captions to Figures}

Figure 1 1a Typical FE model configuration

$1 \mathrm{~b}$ Schematic showing real screw superimposed on FE model

Figure 2 Different levels of radial fill

Figure $3 \quad$ Variation of pull-out force with screw length

Figure $4 \quad$ Variation of pull-out force with pore size

Figure $5 \quad$ Variation of pull-out force with radial augmentation

Figure $6 \quad$ Influence of contact condition a) bonded contact; b) frictional contact

Figure $7 \quad$ Surface demonstrating the effect of augmentation and cortical shell 
Page 14
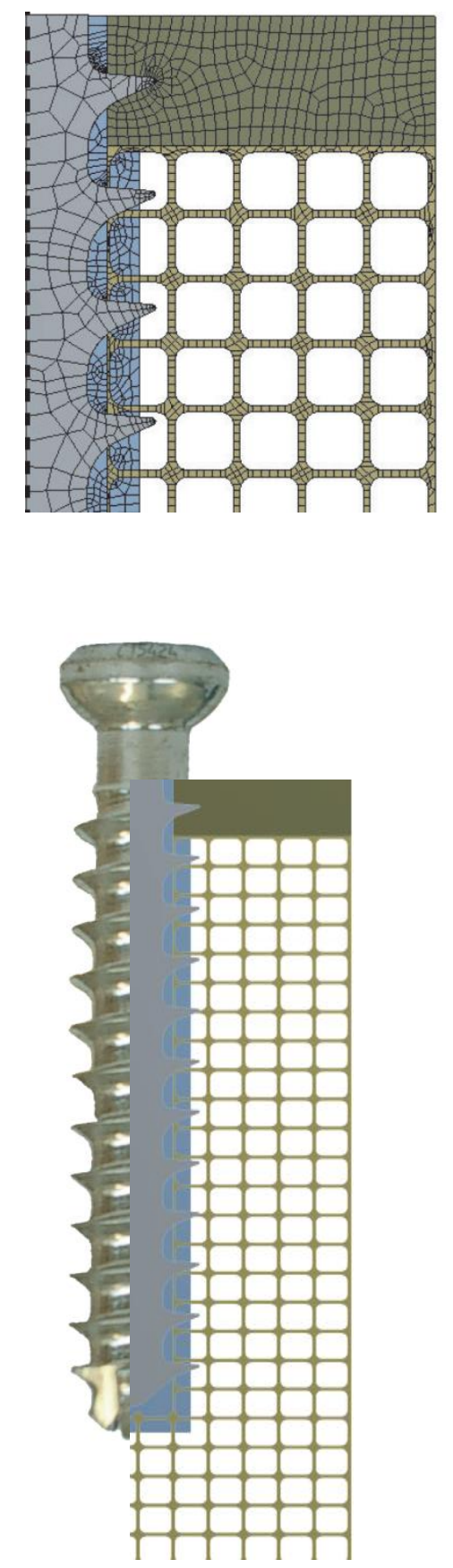


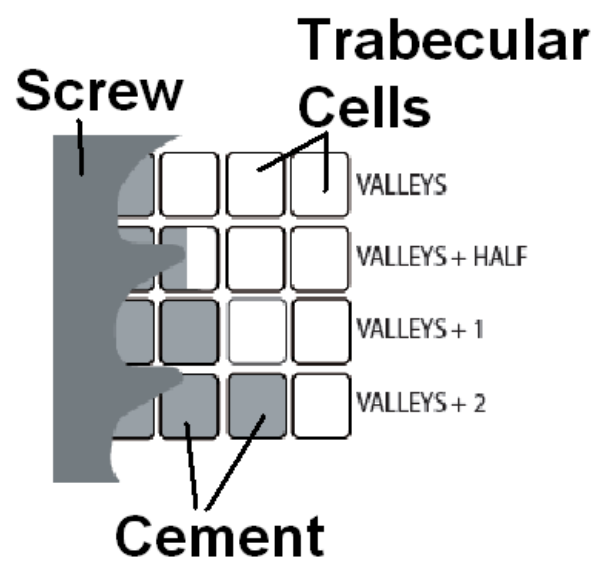

Figure 2 


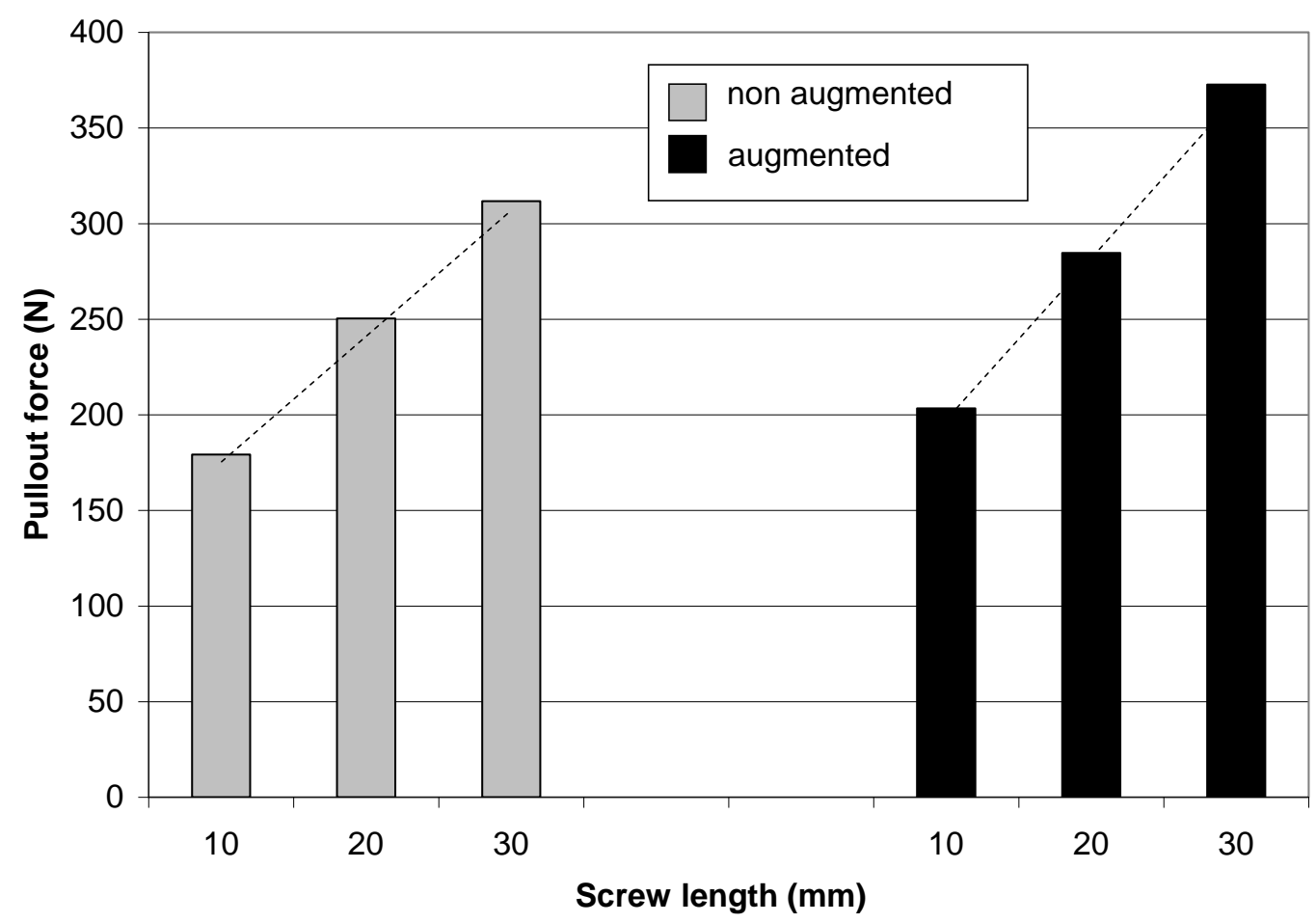

Figure 3

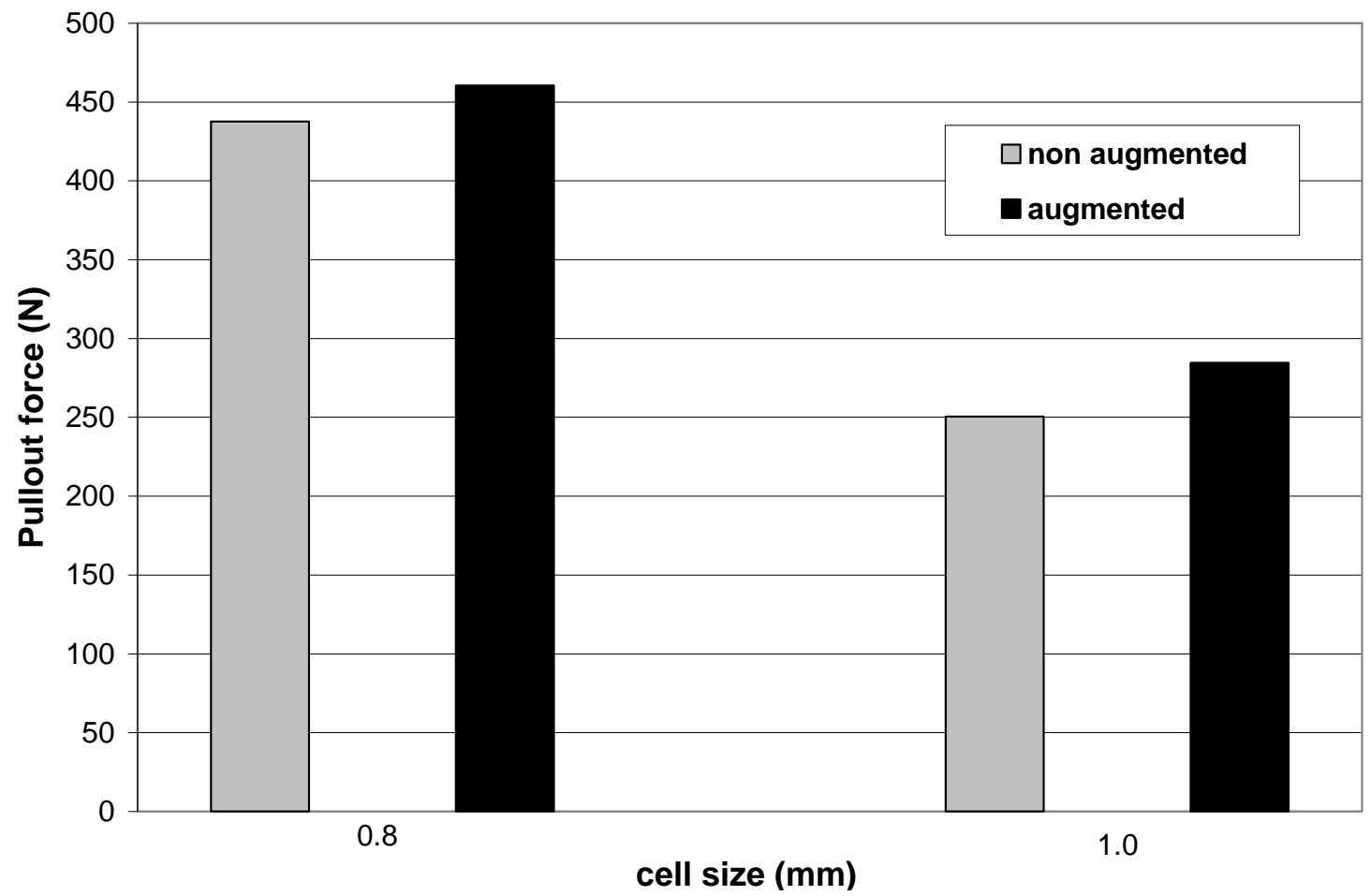

Figure 4 


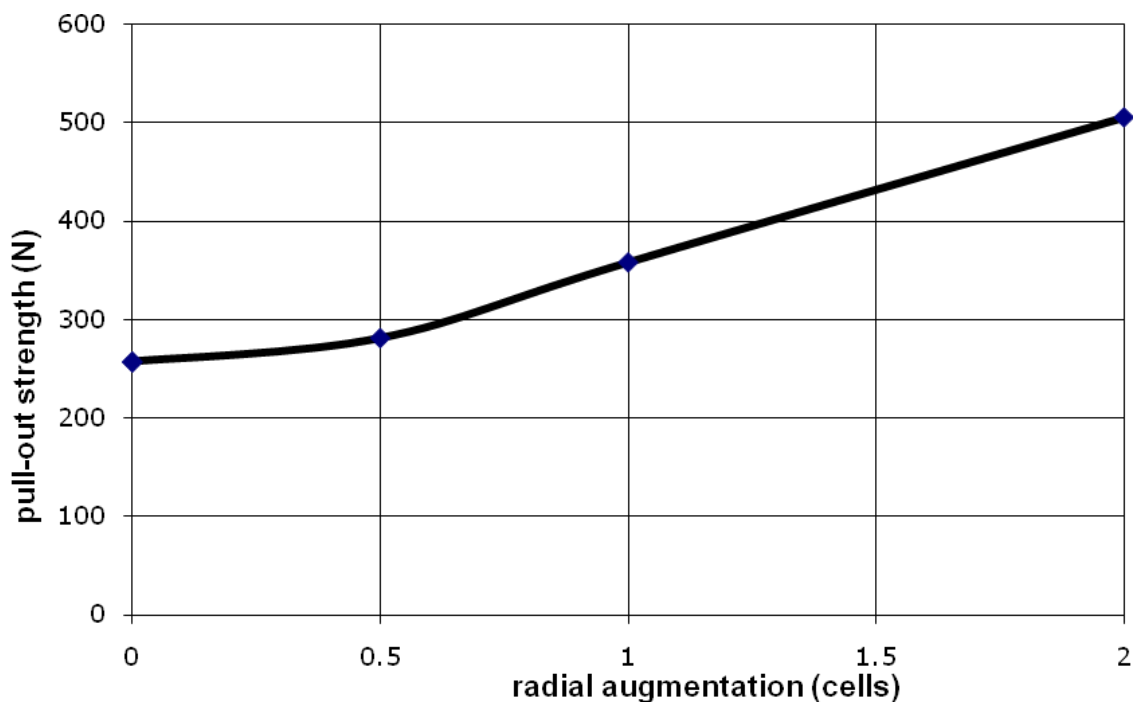

Figure 5 


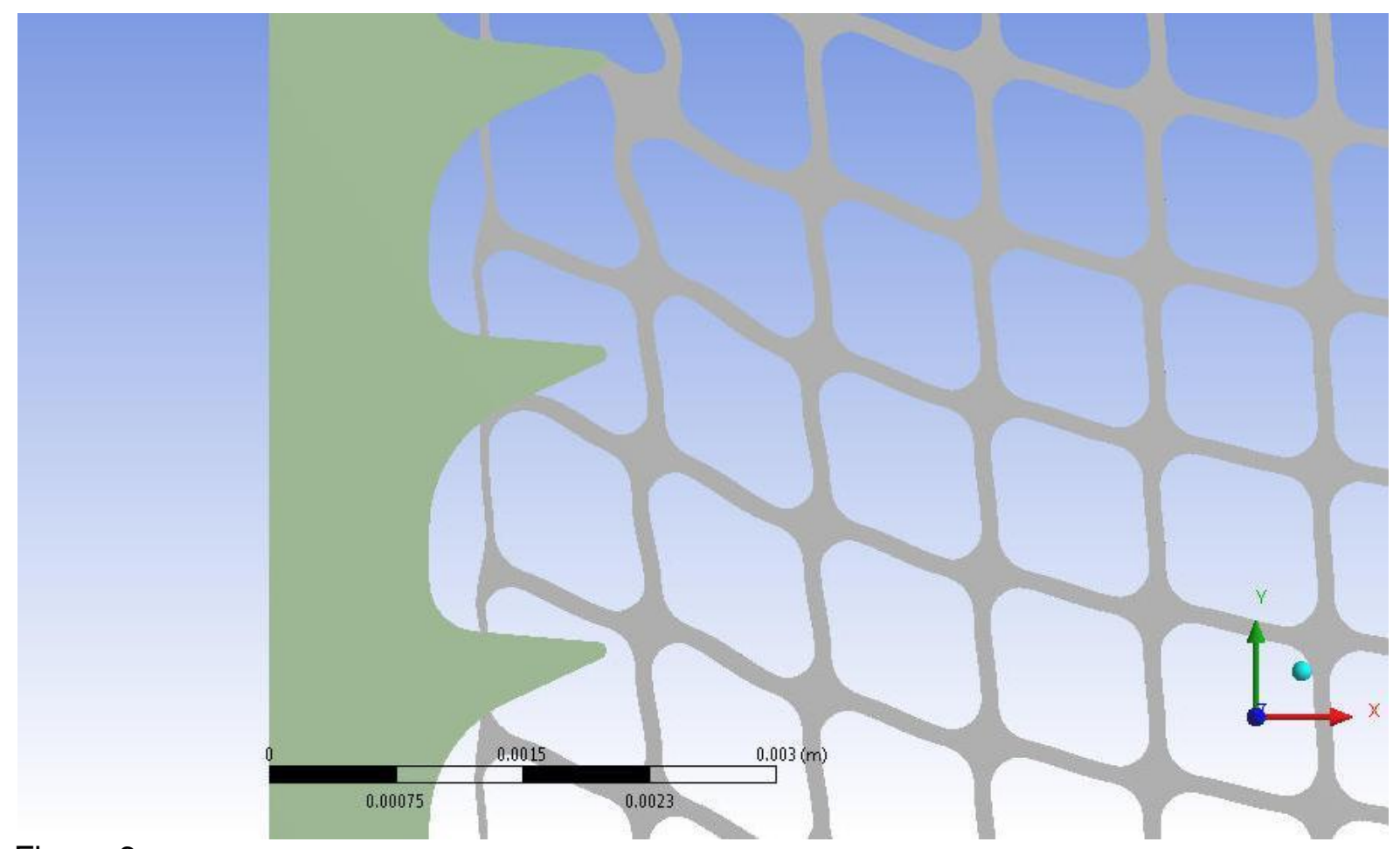

Figure 6a

Figure $6 b$ 


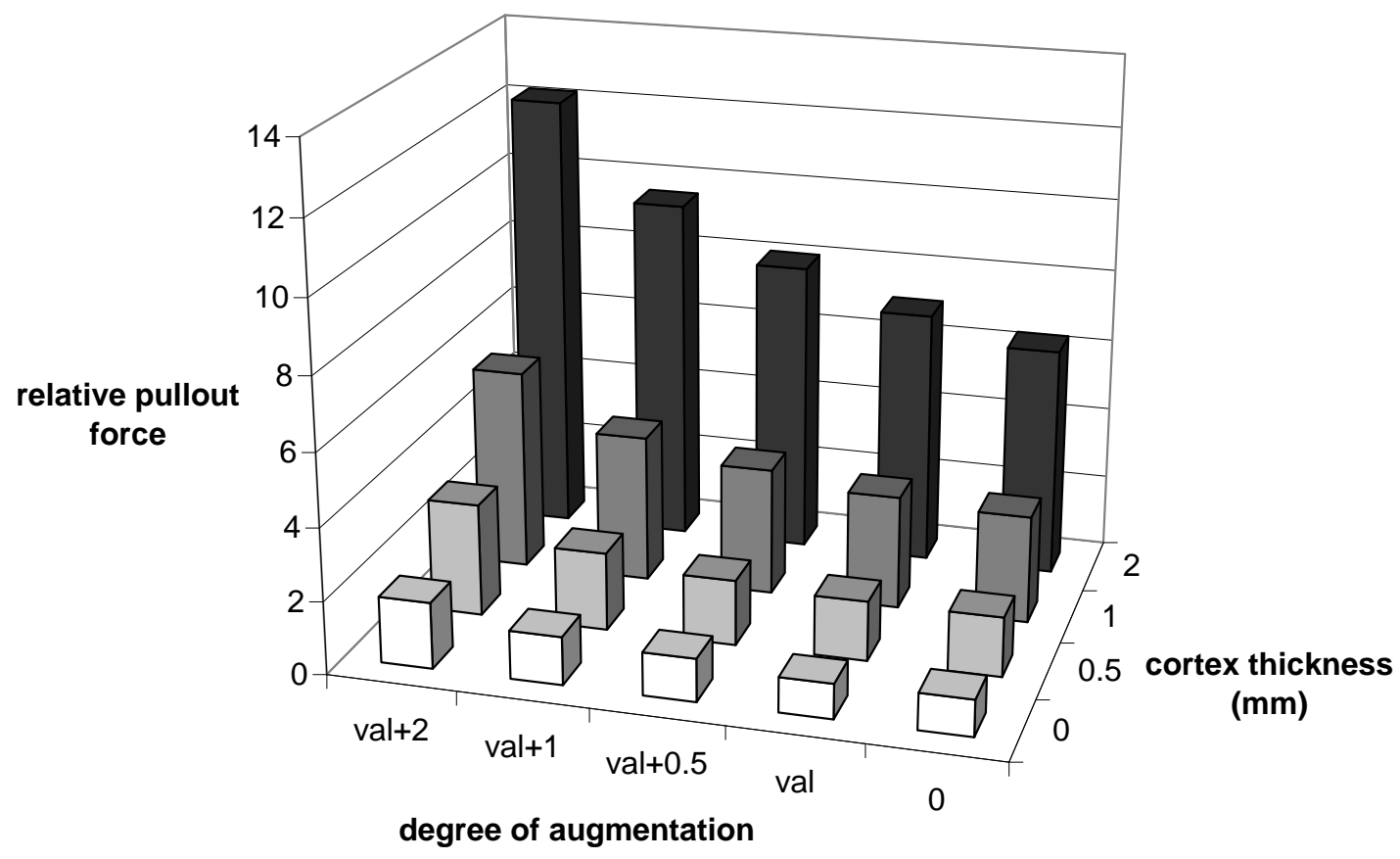

Figure 7 